\title{
MINIREVIEW \\ MATURITY-ONSET DIABETES OF THE YOUNG
}

\author{
Stefan S. Fajans*, Graeme I. Bell**, Donald W. Bowden***, Jeffrey B. Halter*†, Kenneth S. \\ Polonsky††
}

*Department of Internal Medicine, University of Michigan Medical Center and the $\nmid$ Department of Veterans Affairs Medical Center, Ann Arbor, MI, **The Howard Hughes Medical Institute, University of Chicago, Chicago, IL, ***Department of Biochemistry, Bowman Gray School of Medicine, Wake Forest University, Winston-Salem, NC and $\dagger \dagger$ Department of Medicine, University of Chicago, IL

\section{(Received in final form May 25, 1994)}

\begin{abstract}
Summary
Maturity-onset diabetes of the young (MODY) is a subtype of noninsulin dependent diabetes mellitus (NIDDM). It is characterized by an early age of onset and autosomal dominant mode of inheritance. These features and the availability of large multigenerational pedigrees make MODY useful for genetic studies of diabetes. In the large, 5-generational RW pedigree, MODY is tightly linked to genetic markers on chromosome 20q. Affected subjects in this family show abnormalities of carbohydrate metabolism varying from impaired glucose tolerance (IGT) to severe diabetes. Approximately $30 \%$ of diabetic subjects become insulin requiring and vascular complications occur. MODY is also linked to the glucokinase gene on chromosome $7 p$ and many different mutations associated with MODY have been identified in this gene. MODY due to mutations in the glucokinase gene is a relatively mild form of diabetes with mild fasting hyperglycemia and IGT in the majority. It is rarely insulin requiring and rarely has vascular complications. Clinical studies indicate that the genetic or primary defect in MODY is characterized by deranged and deficient insulin secretion and not by insulin resistance and that there are quantitative and qualitative differences in insulin secretory defects which differentiate subjects with MODY due to glucokinase mutations from those with mutations in the gene on chromosome $20 \mathrm{q}$. These differences correlate with the severity of diabetes between these two genetic forms of MODY.
\end{abstract}

Key Words: maturity-onset diabetes of the young, diabetes, genetics, insulin secretion

The purpose of this minireview is to summarize our expanding knowledge of the phenotypic expression, natural history, molecular genetics and pathogenesis of maturity-onset diabetes of the young, abbreviated as MODY. MODY is a relatively uncommon subtype of noninsulindependent diabetes mellitus (NIDDM). It is generally recognized that the latter is a heterogeneous disorder (1). Recent investigations have indicated that MODY is phenotypically and genetically heterogeneous as well. It is a valuable model for the study of the molecular genetics and pathogeneses of NIDDM (2).

Corresponding author: Stefan S. Fajans, M.D., 3920 Taubman Center, Box 0354, University of Michigan Medical Center, Ann Arbor, MI 48109-0354, Telephone: (313) 936-5034, FAX: (313) 936-9240. 


\section{Definition, phenotypic expression and natural history}

MODY is defined as NIDDM characterized by an early age of onset and autosomal dominant mode of inheritance (2-4). The history of the use of this term and its abbreviation have been reviewed previously $(3,4)$. More recently, it has also been referred to as early-onset NIDDM $(5,6)$. When MODY is suspected and family members are examined biochemically, a diagnosis of diabetes can be made almost invariably under the age of 25 years, frequently between the ages of 9-13 years, and in some families at an even earlier age. Because of autosomal dominant inheritance and early age of onset it is possible to collect large multigenerational pedigrees with MODY, a unique feature of this subtype of NIDDM. When MODY pedigrees are studied prospectively, much can be learned about the phenotypic expression and natural history of this type of diabetes.

The RW Pedigree, consisting of more than 360 presently identified members including 72 known subjects with diabetes distributed over 5 generations, has been studied and followed prospectively by one of us (SSF) since 1958. The propositus, II-5 (W branch), offspring of I-3, had diabetes diagnosed at the age of 41 years (Fig. 1A). He was blind from diabetic retinopathy at the age of 61 years and had an amputation for peripheral vascular disease. He had five brothers, four of whom had diabetes and one who did not. Macrovascular disease including myocardial infarctions and peripheral vascular disease with gangrene and amputations, as well as microvascular disease including retinopathy and blindness are complications resulting from MODY in the RW pedigree (Fig. 1). In addition to these, there is also evidence of neuropathy. In 1958, the eleven nonobese, apparently healthy and asymptomatic offspring of II- 5 were recruited for routine blood glucose testing. Seven of the eleven were found to have abnormal glucose metabolism (3). The older three had fasting hyperglycemia (mean $257 \mathrm{mg} / \mathrm{dl}$ ), three others had diabetic glucose tolerance tests without diagnostic fasting hyperglycemia, and one had impaired glucose tolerance (IGT). With follow-up, all have developed fasting hyperglycemia. Two have been treated with insulin because of eventual unresponsiveness to sulfonylurea drugs, four have been treated successfully with sulfonylurea drugs up to the present, and one is using diet alone, although sulfonylurea therapy is indicated because he has recently developed fasting hyperglycemia. Subsequently, by routine blood glucose testing diabetes was diagnosed in 10 of the 20 members of generation IV who are offspring of diabetic subjects of generation III, and up to the present time in four members of generation V. None of them are obese. Ages of diagnosis were 9-14 years in twelve of these patients with diabetes. Patient IV-144 has typical IDDM.

Among offspring of II-2, three of the 5 diabetic members (III-3, III-4, III-8) have MODY segregating in generations III-V (Fig. 1B). Two of the 5 (III-2, III-9) are obese, are hyperinsulinemic, while MODY subjects are generally hypoinsulinemic (see below), and were diagnosed with diabetes at age 48 years in one (III-2) and in the other at age 61 (III-9) by prospective testing. Of the twelve offspring of II-3, six have NIDDM. In none was the diagnosis made before the age of 43 years, although in none was blood glucose testing performed at an earlier age. Moreover, none of the 44 offspring of these six diabetic patients who have been tested have diabetes at the present time. Similarly, none of the four offspring of diabetic II-6 has diabetes, nor do any of their 15 offspring who have been tested. It appears that offspring of II- 5 and some of II-2 exhibit the classic pattern of autosomal dominant inheritance characteristic of MODY, whereas the offspring of II-3 and II-6, as well as III-2 and III-9, do not. Thus, as brought out and confirmed by molecular genetic studies (see below), it appears that heterogeneity of inheritance and type of diabetes appears even in this large pedigree. Sibling II-4 did not have diabetes. None of his 18 offspring of generations III-IV have NIDDM, although one granddaughter has classical IDDM. II-1 had no children.

I-1 (Fig. 1A) had 3 offspring, 2 of whom had diagnosed diabetes (R branch, Generation II, not shown in Figure 1). Among their 10 offspring in generation III, six have or have had diagnosed NIDDM. Of twelve tested subjects in Generation IV who are offspring of a diabetic parent, five have diabetes. Thus, diabetes is inherited in the autosomal pattern of MODY in the R branch as well. None of them are obese. 


\section{PEDIGREE R-W}

A

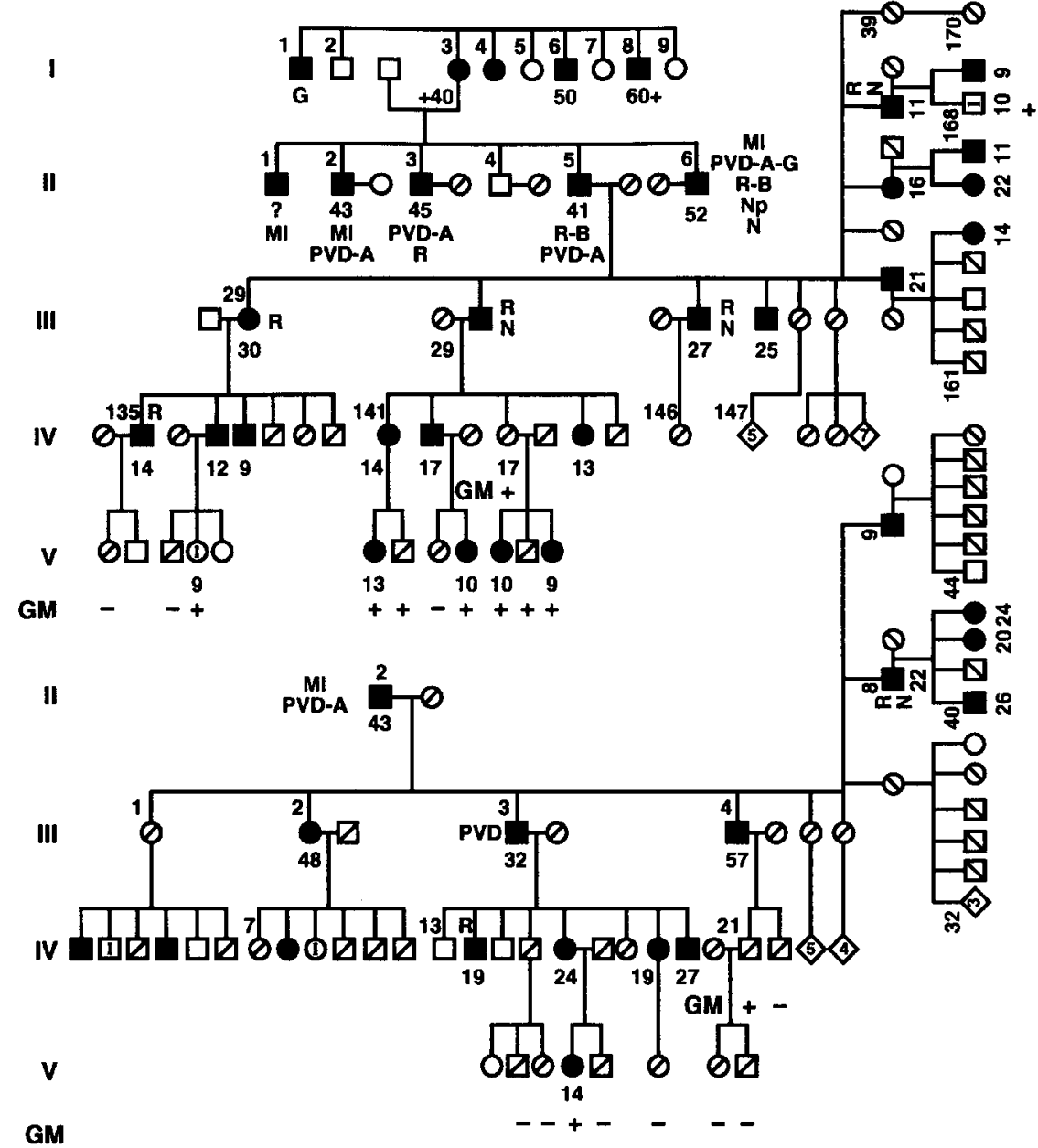

Fig. 1

Partial pedigree of the RW family. Offspring of I-1 belong to the R branch. Offspring of I-3 belong to the W branch. Only the offspring of II-5 (A) and II-2 (B) of the W branch are shown. All subjects with diabetes were or are non-insulin dependent except IV-144 who is insulin-dependent. Diabetic or IGT offspring of II-5 of generations III$\mathrm{V}$ (A) and diabetic offspring III-3 and III-8 (B) and their diabetic offspring are genetic marker (chromosome 20) positive. In addition, nondiabetic IV-143 (A) and IV-21 (B) are genetic marker (GM) positive (+). In generation $V, G M+$ or negative $(-)$ are indicated (A, B). Numbers above male diabetic members $(\square)$ or female diabetic members ( $)$ are number in generation and those below are ages at diagnosis. I, Impaired glucose tolerance; $\boldsymbol{\emptyset}$, normal glucose tolerance; $\square$, reported normal and untested; $\$$ groups of siblings untested and of unspecified sex with number of individuals given; $M I$, myocardial infarction; $P V D$, peripheral vascular disease; $A$, amputation; $G$, gangrene, $N$, neuropathy, $A n g$, angina pectoris; $R$, retinopathy; $R-B$, retinopathy and blindness; $N P$, nephropathy. All diabetic members of generations I and II, along with III-29 and III-30, are deceased. 
MODY is usually asymptomatic in younger age groups, although some patients may have symptoms, particularly if stressed by an infection. Unless searched out by prospective testing, because of a family history of NIDDM in 2 or more generations, in a young person or during a pregnancy, a clinical diagnosis of diabetes is frequently not made in many members of such families until middle or late adult life. Thus, age of diagnosis cannot be equated to age of onset of hyperglycemia. Multigenerational pedigrees of NIDDM, suggestive of MODY, have been described in whom not a single affected subject was diagnosed under the age of 29 years but in whom molecular genetic studies disclosed a MODY-related mutation $(7,8)$. The impression that such mutations may ozcur in late-onset diabetes may be more apparent than real. Younger family members must be screened before typical MODY can be excluded. As demonstrated in the RW Pedigree in which MODY is linked to chromosome $20 \mathrm{q}$ (see below), it can be demonstrated by repeated testing in younger members that there may be a variable rate of progression from nondiagnostic (but not normal) glucose tolerance tests to IGT, from IGT to diabetic glucose tolerance with normal fasting plasma glucose levels (up to 18 years), and very slow or rapid progression to fasting hyperglycemia ( 0.5 to 27 years). Severity of carbohydrate intolerance may fluctuate for many years particularly in patients with mild abnormalities before the onset of persistent fasting hyperglycemia. In contrast, other individuals with MODY from this pedigree may have fasting hyperglycemia or rapid progression from an early age, even though they are asymptomatic. Among nonobese diabetic subjects of the RW Pedigree in generations III-V approximately $80 \%$ have had fasting hyperglycemia at diagnosis or on followup. Plasma glucose levels at first detection of fasting hyperglycemia range between 140 to 366 $\mathrm{mg} / \mathrm{dl}$. Approximately $30 \%$ had fasting hyperglycemia diagnosed between the ages of 9 and 14 years or within a 1 to 3 year follow-up.

Fasting hyperglycemia, even at a young age ( 9 to 14 years), may be responsive to either diet therapy alone, or diet plus oral agents for a few years or decades $(3,4,9)$. With sulfonylurea therapy, glucose-induced insulin secretion showed an average increase of $68 \%$ in diabetic patients who remained responsive to chlorpropamide up to 33 years (9). In most patients, however, glucose-induced insulin secretion declines over time (1 to $4 \%$ per year). Some patients (9-13 years of age at diagnosis) become unresponsive to maximal doses of sulfonylureas after 3 to 25 years and then have very small or no increases in glucose-induced insulin secretion. They require treatment with insulin to normalize fasting hyperglycemia (not insulin-dependent or ketotic and islet cell antibody-negative diabetes). At that point, some of these patients have very low fasting C-peptide levels, absence of nutrient-stimulated C-peptide levels and an unstable type of diabetes resembling that seen in insulin-dependent diabetes (IDDM). Among the known diabetic patients from generations III-V of the RW Pedigree approximately $30 \%$ have become insulin-requiring. Typical microangiopathic and macroangiopathic complications may occur similar to those seen in other patients with $\operatorname{NIDDM}(3,4)$.

In contrast to MODY linked to chromosome $20 \mathrm{q}$, as present in the RW pedigree, MODY due to mutations in the glucokinase gene on chromosome $7 \mathrm{p}$ (see below) is a relatively mild form of diabetes with mild fasting hyperglycemia and IGT in the majority that may be recognized by biochemical testing at an even younger age (mean $7 \pm 4$ years, minimal age, 1 year) (10). There appears to be little progression of hyperglycemia on follow-up $(11,12)$. Severe fasting hyperglycemia and vascular complications appear to be infrequent (Table 1). Thus MODY due to glucokinase mutations appears to be a much milder and relatively benign form of hyperglycemia, in contrast to the more severe diabetes seen in MODY linked to chromosome $20 \mathrm{q}$ that more closely resembles classical NIDDM.

\section{Molecular genetics of MODY}

MODY fulfills some of the fundamental requirements for defining the molecular genetic basis of any disorder by linkage analysis because of its established autosomal dominant inheritance and the availability of large multigenerational kindreds. The RW Pedigree was first used for a search of diabetes susceptibility genes by this technique. The initial linkage strategy was to search for "candidate genes", that is genes involved in carbohydrate and lipid metabolism. Candidate genes excluded as the cause of NIDDM in the RW Pedigree include the insulin, glucagon, islet amyloid polypeptide, insulin-like growth factors 1 and 2 , insulin receptor, low-density 
lipoprotein receptor, glucose transporters, apolipoproteins, lipoprotein lipase, hexokinase 1 genes and the major histocompatibility complex (13). In a subsequent systematic gene mapping approach (positional cloning), DNA polymorphisms in the adenosine deaminase gene (ADA) and the anonymous locus D20S16 on the long arm of chromosome 20 were found to cosegregate with MODY $(5,13-17)$ in members with diabetes of both $\mathrm{W}$ and $\mathrm{R}$ branches. There are no recombinations between these markers and MODY and the lod score presently exceeds 17.0 at a recombination fraction of 0.00 indicating that the gene responsible for MODY in this family is tightly linked to these genes. In the W branch, the descendants of II-3 who have NIDDM do not carry the at-risk ADA and D20S16 markers, suggesting that they do not have MODY but another form of NIDDM (13-17). In addition, two of five diabetic offspring of II-2 (III-2 and III-9) who are obese and in whom diabetes was diagnosed at the age of 48 and 61 years, respectively, do not carry these markers.

Two subjects (IV-143 and IV-21) in the W branch of the RW pedigree who are over the age of 25 years are nondiabetic but carry the ADA and D20S16 markers. Thus, these two subjects are nonpenetrant $(5,13)$. IV-143 had one glucose tolerance test (GTT) characteristic of IGT and one of diabetes at ages 16-17 years but for the following 19 years each GTT has been normal even though she has a low insulin response to orally administered glucose. She is very lean, active, and has increased sensitivity to insulin during the frequently sampled intravenous glucose tolerance test (Bergman's minimal model). During a prolonged low dose glucose infusion, she became markedly hyperglycemic.

The identification of genetic markers for MODY in the RW Pedigree has shown that linkage studies of large MODY families can uncover DNA markers for NIDDM $(2,13,15)$. The gene responsible for MODY in the RW Pedigree is unknown but is in the region of ADA and D20S16 on chromosome 20q. Finding genetic markers is proof at the molecular level that genetic factors play an important role in the causation of MODY. DNA typing can identify at risk subjects, i.e., genetic screening for prediabetes is possible in the RW Pedigree. MODY is not fully penetrant suggesting that environmental factors may also play a role in its development. Identification of the MODY gene on chromosome 20 may disclose previously unrecognized mechanisms controlling insulin secretion and lead us closer to an understanding of the pathogenesis of MODY in this pedigree, with possible application to NIDDM in general. Such studies may lead eventually to the prevention, improved treatment, or even a cure for this and other forms of NIDDM.

NIDDM may have different causes even in a single family. Previous clinical characterization (also see Insulin secretion below) has suggested heterogeneity of the diabetes in the RW Pedigree which was confirmed by the molecular genetic studies. The results of these studies support the inclusion of autosomal dominant inheritance in the definition of MODY. The RW Pedigree includes two patients with IDDM, one a granddaughter of II-5 and the other a granddaughter of nondiabetic II-4. Because neither of these patients carry the genetic markers for MODY, this finding provides evidence that the MODY susceptibility gene does not contribute to IDDM in this pedigree (13). Because there is heterogeneity between MODY families by hormonal and metabolic characterization (18), it was postulated that additional NIDDM susceptibility genes or modifying determinants would be found (13). Indeed, this occurred shortly thereafter.

Tight linkage between MODY and the glucokinase gene on chromosome $7 p$ was found in approximately $60 \%$ of 32 French MODY families $(6,10)$, in one British family $(7,11)$ and in two Japanese families $(19,20)$. Glucokinase is the first rate-limiting enzyme in the metabolism of glucose by the pancreatic beta-cell. It causes the phosphorylation of glucose to glucose-6phosphate initiating glycolysis which is essential for insulin secretion. This enzyme has been postulated to be the glucose sensing mechanism for insulin secretion (21). Subsequently, a host of different mutations (nonsense, missense or deletions) in the glucokinase gene have been found in members of MODY families in which MODY is linked to the glucokinase gene $(7,10,19,20,22-25)$. They are believed to cause diabetes by a gene dosage mechanism with a modest decrease in glucokinase activity increasing the glucose threshold for insulin secretion. Matschinsky has suggested that a $15 \%$ decrease in glucokinase activity may raise the threshold 
of insulin secretion from 5 to $6 \mathrm{mmol}(21)$. Mutations in the glucokinase gene are the most common genetic cause of NIDDM identified to date, particularly among MODY pedigrees. In one French $(6,22)$ and one British (7) glucokinase-linked MODY pedigrees, there was also evidence for genetic heterogeneity in that some diabetic subjects had not inherited the mutant glucokinase allele. The RW pedigree is the only large pedigree in which tight linkage of MODY to chromosome $20 \mathrm{q}$ has been established. Evidence consistent with linkage to chromosome 20q has been found in two French $(6,10)$ and one Canadian (D.W. Bowden, E. Colle, unpublished results) MODY pedigrees.

Finally, in addition to the glucokinase gene and the gene on chromosome 20, there must be other loci that can cause MODY as MODY pedigrees have been described that show no evidence of linkage with glucokinase or markers on chromosome $20(5,6,10,11)$.

\section{B-cell function and insulin resistance}

In the RW pedigree, the majority of MODY subjects who were offspring of II-2 and II-5 have a delayed and subnormal insulin secretory response to orally administered glucose, suggesting strongly an impairment of B-cell function. In these individuals, impaired B-cell function, although moderate in magnitude, appears to the be the major underlying pathogenetic factor for abnormal glucose levels. The low insulin secretory response to glucose may occur from childhood on and before glucose intolerance appears. It was postulated to be a manifestation of the basic genetic defect that leads to diabetes only when additional superimposed environmental factors supervene $(3,4)$. A number of environmental determinants superimposed on genetic factors may lead to the appearance of IGT or NIDDM in predisposed individuals. In this MODY pedigree the important factors appear to be a decreasing physiological insulin sensitivity, without the normally associated increase in insulin secretion, as occurs with increasing age, growth and increasing body mass, and puberty, as well as a further gain in weight without developing obesity when subjects progress from adolescence to young adult age $(3,4)$. In addition, as mentioned above, glucose-induced insulin secretion may decline further over time (9). Pathological insulin resistance does not appear to be an important contributing factor because of normal sensitivity to intravenously administered insulin and because of the usually low insulin requirement in insulin-treated diabetic members of the RW Pedigree. In contrast, the diabetic but non-MODY offspring of II-3 and the non-MODY diabetic offspring of II-2 are hyperinsulinemic, differentiating them from the offspring of II- 2 and II- 5 who have MODY.

In diabetic MODY patients linked to a mutation in the glucokinase gene, there is evidence of decreased insulin secretion by continuous glucose infusion $(11,12,26)$ although the acute insulin response to glucose was within normal limits $(12,26)$. A decreased insulin secretory response to orally administered glucose has also been reported in glucokinase-linked MODY (20). In addition, no evidence of insulin resistance has been reported $(12,26)$ in such patients. This is in contradistinction to patients with other types of NIDDM, most of whom are obese, in whom it has been found or postulated that insulin resistance is a more important factor than insulin deficiency in the pathogenesis of diabetes $(27,28)$.

Since chronic hyperglycemia has been reported to be associated with both a decrease of insulin sensitivity as well as an impairment of B-cell function, the question of which is the primary genetic defect in MODY or NIDDM is very difficult to address in diabetic patients (27). Since we now have genetic markers for MODY in the RW Pedigree, we undertook to determine early abnormalities of insulin action and of insulin secretion in nondiabetic subjects of the pedigree with and without the gene markers to ascertain which of these defects might be primary. Six nondiabetic marker-negative and 5 nondiabetic marker-positive members of the RW Pedigree were studied, as were 4 mildly diabetic marker-positive family members. Unrelated, young, healthy subjects served as comparison groups (29). Insulin action and insulin secretion were assessed with a frequently sampled intravenous glucose tolerance test (Bergman Minimal Model). Insulin secretion was further assessed during constant low dose glucose infusion by deconvolution of plasma $\mathrm{C}$-peptide and by pulse analysis. The nondiabetic marker-positive group had normal sensitivity to insulin and unimpaired acute insulin response to intravenous 
glucose. However, the nondiabetic marker-positive group had decreased mean plasma C-peptide concentration and reduced absolute amplitude of insulin secretory ultradian oscillations and decreased insulin secretion rate during prolonged glucose infusion (Fig. 2). These responses to prolonged glucose infusion were similar to those observed in the diabetic group, who, in addition, also had a decreased or absent acute insulin response to intravenous glucose (29). No alterations of insulin secretion were observed in the nondiabetic marker-negative family members or in the comparison groups. Deranged and deficient insulin secretion, and not insulin resistance, appears to be the genetic or primary abnormality that characterizes nondiabetic individuals who are predisposed to MODY in the RW pedigree. Prolonged glucose infusion studies may reveal qualitative and quantitative defects in insulin secretion not identified by the acute insulin response to intravenous glucose. Furthermore, use of the acute insulin response to glucose may not be able to exclude a primary beta-cell defect in the pathogenesis of any form of NIDDM (29).
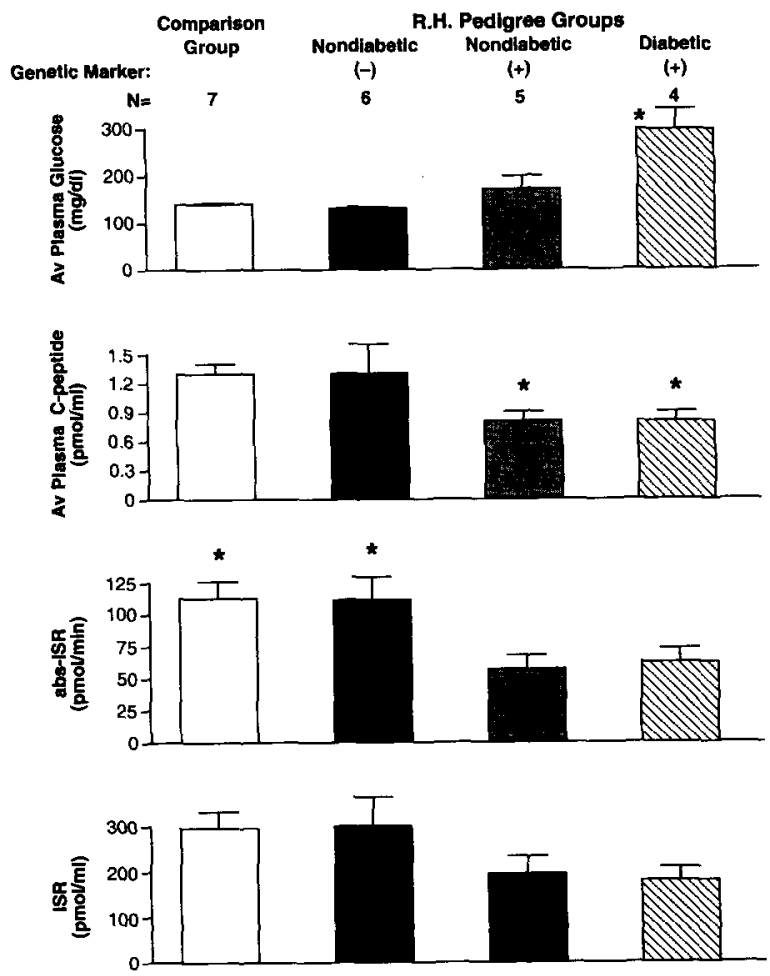

Fig. 2

Average plasma glucose and C-peptide and ultradian oscillation of insulin secretion (abs-ISR) and insulin secretion rate (ISR) during constant 16-hour glucose infusion (29).

Av. glucose Av. C-peptide abs-ISR
$* \mathrm{p}<0.05$ vs other groups

$* \mathrm{p}<0.05$ vs comparison group

$* \mathrm{p}<0.05$ vs. nondiabetic and diabetic marker $(+)$ groups

Quantitative and qualitative differences in insulin secretory defects between MODY with glucokinase mutations and MODY with mutation on chromosome $20 \mathrm{q}$ have been found by studies with acute and more prolonged intravenous infusions of glucose. MODY subjects with glucokinase mutations have a first phase insulin response to glucose which is in the normal 
range $(12,26)$ while mildly diabetic patients with a chromosome 20 mutation have a decreased or absent acute insulin response to glucose (29). During graded intravenous glucose infusions, both groups of MODY subjects (including nondiabetic marker-positive subjects of the RW pedigree) showed a decreased response of the beta-cell to glucose resulting in a downward shift in the glucose/insulin secretion rate dose response curve to the right which, in preliminary studies, was more severe in RW subjects with a failure of beta cell sensitivity to improve after prolonged priming with intravenous glucose (26; M. Byrne, S. Fajans, A. Stolz, J. Ortiz, R. Sobel and K. Polonsky, Diabetes, June 1994, abstract). Although the specific genetic defect causing MODY in the RW pedigree is unknown, the pattern of altered insulin secretion in these subjects suggests a unique mechanism of the B-cell dysfunction which may distinguish this form of MODY from that due to mutations in the glucokinase gene (Table 1). The greater severity of the insulin secretory defect in diabetic and mildly diabetic subjects with mutation in the diabetes susceptibility gene on chromosome $20 \mathrm{q}$ correlates with a greater severity of hyperglycemia, a greater need for insulin therapy and a greater prevalence of vascular complications seen in these diabetic subjects than in those with mutations in the glucokinase gene (Table 1).

\section{TABLE I}

Differences between MODY due to Mutations in the Glucokinase Gene (Chromosome 7p) and the Diabetes-Susceptibility Gene on Chromosome $20 \mathrm{q}$

Glucokinase Gene

Fasting hyperglycemia (> $140 \mathrm{mg} / \mathrm{dl}$ )

Postprandial hyperglycemia

Minimum age at diagnosis

Need for Insulin Therapy

Vascular Complications

$\mathrm{AIR}_{\text {glu }}^{*}$

$\mathrm{ISR}^{\dagger}$ during graded IV glucose infusion mildly diabetic subjects nondiabetic subjects with genetic markers

$$
\begin{aligned}
& 0-++ \\
& 0-++
\end{aligned}
$$

1 year

Uncommon (2\%)

Rare

Normal

$$
\downarrow-\downarrow \downarrow
$$

Not available

Normal (45\% increase)
Chromosome 20q

$0-++++$ (approx. 80\%)

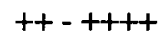

$7-9$ years

Common (approx. 30\%)

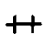

$\downarrow \downarrow$ - absent

$\downarrow \downarrow \downarrow$

$\downarrow \downarrow \downarrow$

Absent

\footnotetext{
*AIR glu - acute insulin response to glucose

†ISR - insulin secretion rate
}

\section{Acknowledgements}

This work was supported by grants from the National Institutes of Health to the Michigan Diabetes Research and Training Center (DK-20572), the Claude D. Pepper Geriatric Research and Training Center (AG-08808), the University of Michigan General Clinical Research Center (MO1RR-00042), the Medical Research Service of the Department of Veterans Affairs, RO1- 
DK41269 (D.W.B.) and the University of Chicago Diabetes Research and Training Center (DK20595), Howard Hughes Medical Institute, General Clinical Research Center (RR-00055) and RO1-DK31842 (K.S.P.), The University of Chicago.

\section{References}

1. S.S. FAJANS, M.C. CLOUTIER, R.L. CROWTHER. Diabetes 27 1112-1125 (1978).

2. S.S. FAJANS, G.I. BELL, D.W. BOWDEN. J. Lab. Clin. Med. 119 206-210 (1992).

3. S.S. FAJANS. Diabetes/Metabolism Reviews 5 579-606 (1989).

4. S.S. FAJANS. Diabetes Care 13 49-64 (1990). (Erratum 13:910, 1990).

5. D.W. BOWDEN, G. AKOTS, C.B. ROTHSCHILD, K.F. FALLS, M.J. SHEEHY, C. HAYWARD, A. MACKIE, J. BAIRD, D. BROCK, S.E. ANTONARAKIS, S.S. FAJANS. Am. J. Hum. Genet. 50 607-618 (1992).

6. P.H. FROGUEL, M. VAXILLAIRE, F. SUN, G. VELHO, H. ZOUALI, M.O. BUTEL, S. LESAGE, N. VIONNET, K. CLEMENT, F. FOUGEROUSSE, Y. TANIZAWA, J. WEISSENBACH, J.S. BECKMANN, G.M. LATHROP, P.H. PASSA, M.A. PERMUTT, D. COHEN. Nature 356 162-164 (1992).

7. M. STOFFEL, P. PATEL, Y-M.D. LO, A.T. HATTERSLEY, A.M. LUCASSEN, R. PAGE, J.I. BELL, G.I. BELL, R.C. TURNER, J.S. WAINSCOAT. Nature Genetics 2 153$156(1992)$.

8. H. KATAGIRI, T. ASANO, H. ISHIHARA, K. INUKAI, M. ANAI, J. MIYAZAKI, K. TSUKUDA, M. KIKUGHI, Y. YAZAKI, Y. OKA. Lancet 340 1316-1317 (1992).

9. S.S. FAJANS, M.B. BROWN. Diabetes Care 16 1254-1261 (1993).

10. P. FROGUEL, H. ZOUALI, N. VIONNET, F. VELHO, M. VAXILLAIRE, F. SUN, S. LESAGE, M. STOFFEL, J. TAKEDA, P. PASSA, M.A. PERMUTT, J.S. BECKMANN, G.I. BELL, D. COHEN. N. Eng. J. Med. 328 697-702 (1993).

11. A.T. HATTERSLEY, R.C. TURNER, M.A. PERMUTT, P. PATEL, Y. TANIZAWA, K.C. CHIU, S. O'RAHILLY, P.J. WATKINS, J.S. WAINSCOAT. Lancet $\underline{399}$ 1307-1310 (1992).

12. G. VELHO, P. FROGUEL, K. CLEMENT, M.E. PUEYO, B. RAKOTOAMBININA, H. ZOUALI, P. PASSA, D. COHEN, J.J. ROBERT. Lancet 340 444-448 (1992).

13. G.I. BELL, K.S. XIANG, M.V. NEWMAN, S.H. WU, L.G. WRIGHT, S.S. FAJANS, R.S. SPIELMAN, N.J. COX. Proc. Natl. Acad. Sci. USA 88 1484-1488 (1991).

14. N.J. COX, K.S. XIANG, S.S. FAJANS, G.I. BELL. Diabetes $41401-407$ (1992).

15. D.W. BOWDEN, T.C. GRAVIUS, G. AKOT, S.S. FAJANS. Diabetes 41 88-92 (1992).

16. C.B. ROTHSCHILD, G. AKOTS, S.S. FAJANS, D.W. BOWDEN. Genomics $\underline{13}$ 560-564 (1992).

17. C.B. ROTHSCHILD, G. AKOTS, R. HAYWORTH, M.J. PETTENATI, P.N. RAO, P. WOOD, F.M. STOLZ, I. HANSMANN, K. SERINO, T.P. KEITH, S.S. FAJANS, D.W. BOWDEN. Am. J. Hum. Genet. 52 110-123 (1993).

18. S.S. FAJANS. Horm. Metabol. Res. 19 591-599 (1987).

19. H. SAKURA, K. ETO, H. KADOWAKI, K. SIMOKAWA, H. UENO, N. KODA, Y. FUKUSHIMA, Y. AKANUMA, Y. YAZAKI, T. KADOWAKI. J. Clin. Endo. Metab. 75 1571-1573 (1992).

20. F. SHIMADA, H. MAKINO, N. HASHIMOTO, M. TAIRA, S. SEINO, G.I. BELL, A. KANATSUKA, S. YOSHIDA. Diabetologia 36 433-437 (1993).

21. F.M. MATSCHINSKY. Diabetes 39 647-652 (1990).

22. N. VIONNET, M. STOFFEL, J. TAKEDA, K. YASUDA, G.I. BELL, H. ZOUALI, S. LESAGE, G. VELHO, F. IRIS, P.H. PASSA, P.H. FROGUEL, D. COHEN. Nature $\underline{356}$ 721-722 (1992).

23. M. STOFFEL, P.H. FROGUEL, J. TAKEDA, H. ZOUALI, N. VIONNET, S. NISHI, I.T. WEBER, R.W. HARRISON, S.J. PILKIS, S. LESAGE, M. VAXILLAIRE, G. VELHO, F. SUN, F. IRIS, P.H. PASSA, D. COHEN, G.I. BELL. Proc. Natl. Acad. Sci. USA $\underline{89} 7698-$ 7702 (1992).

24. F. SUN, B. KNEBELMANN, M.E. PUEYO, H. ZOUALI, S. LESAGE, M. VAXILLAIRE, P.H. PASSA, D. COHEN, G. VELHO, C. ANTIGNAC, P. FROGUEL. J .Clin. Invest. 22 1174-1180 (1993). 
25. M. GIDH-JAIN, J. TAKEDA, L.Z. XU, A.J. LANGE, N. VIONNET, M. STOFFEL, P. FROGUEL, G. VELHO, F. SUN, D. COHEN, P. PATEL, Y-M.D. LO, A.T. HATTERSLEY, H. LUTHMAN, A. WEDELL, R. ST. CHARLES, R.W. HARRISON, I.T. WEBER, G.I. BELL, S.J. PILKIS. Proc. Natl. Acad. Sci. USA 90 1932-1936 (1993).

26. M.M. BYRNE, J. STURIS, K. CLEMENT, N. VIONNET, M.E. PUEYO, M. STOFFEL, J. TAKEDA, P.H. PASSA, D. COHEN, G.I. BELL, G. VELHO, P.H. FROGUEL, K. POLONSKY. J. Clin. Invest. 93 1120-1130 (1994).

27. R.A. DEFRONZO, R.C. BONADONNA, E. FERRANNINI. Diabetes Care 15 318-368 (1992).

28. S. LILLIOJA, D.M. MOTT, M. SPRAUL, R. FERRARO, J.E. FOLEY, E. RAVUSSIN, W.C. KNOWLER, P.H. BENNETT, C. BOGARDUS. N. Eng. J. Med. $\underline{329}$ 1988-1992 (1993).

29. W.H. HERMAN, S.S. FAJANS, F.J. ORTIZ, M.J. SMITH, J. STURIS, G.I. BELL, K.W. POLONSKY, J.B. HALTER. Diabetes 43 40-46 (1994). 